\title{
Didática freiriana: um reencontro com a pedagogia do oprimido
}

\author{
Freirean didactics: reliving the pedagogy of the oppressed
}

\author{
Didáctica freiriana: un re-encuentro con la pedagogía del oprimido
}

\author{
Ivo Dickmann ${ }^{*}$ \\ Ivanio Dickmann
}

\section{Resumo}

Este artigo é resultado de nossa práxis com a Didática Freiriana e quer ser um avanço na reflexão sobre o processo de reinvenção do Método Paulo Freire. Para tanto, temos como base teórico-prática três matizes: a Teologia da Libertação, a Educação Libertadora e a Filosofia da Libertação, por considerar essas três fontes como referências da produção de uma epistemologia latino-americana que se encontra na base da práxis de Paulo Freire na produção da Pedagogia do Oprimido. Do ponto de vista metodológico, vamos descrever três maneiras de utilizar a didática freiriana em diversos espaços e situações pedagógicas, seja na escola, na universidade ou em espaços não formais e informais, são eles: estratégia pedagógica, percurso educativo e "caixa de ferramentas". Embora criada há pouco tempo, a didática freiriana vem se demonstrando com potencial de reinvenção do Método Paulo Freire, tendo como base teórica as contribuições da Pedagogia do Oprimido.

Palavras-chave: Didática freiriana. Método Paulo Freire. Pedagogia do Oprimido. Reinvenção.

\section{Abstract}

This article is the result of our practice with Freirian Didactics and wants to be an advance in the reflection on the process of reinventing the Paulo Freire Method. For that, we have as theoretical and practical basis three nuances: Liberation Theology, Liberating Education and the Philosophy of Liberation, considering these three sources as a reference for the production of a Latin American epistemology that is at the base of Freire's praxis in the production of Pedagogy of the Oppressed. From a methodological point of view, we will describe three ways of using Freirian Didactics in different pedagogical spaces and situations, whether at school, university or in non-formal and informal spaces, they are: pedagogical strategy, educational path and "toolbox". Although created a short time ago, Freirian Didactics have shown themselves to have the potential to reinvent the Paulo Freire Method, based on the theoretical contributions of Pedagogy of the Oppressed.

Keywords: Freirian Didactics. Paulo Freire Method. Pedagogy of the oppressed. Reinvention.

Recebido em 04/06/2020 - Aprovado em 28/09/2020

http://dx.doi.org/10.5335/rep.v27i3.12376

Pós-doutor em Educação pela Uninove, SP. Doutor e mestre em Educação pela Universidade Federal do Paraná. Professor Titular do Programa de Pós-Graduação em Educação e do Programa de Pós-Graduação em Ciências da Saúde na Unochapecó, SC. Orcid: https://orcid.org/0000-0002-6293-8382. E-mail: educador.ivo@unochapeco.edu.br

** É Historiador e Mestre em Serviço Social pela PUC-SP. Editor Chefe da Editora Diálogo Freireano. Assessor e Mentor de Organizações Não Governamentais. Estudioso de Paulo Freire e da Educação Popular, bem como da Economia Solidária, Cooperativismo e Negócios Sociais. Orcid: https://orcid.org/0000-0001-5292-3235. E-mail: ivanio.dialogar@ gmail.com 


\section{Resumen}

Este artículo es el resultado de nuestra práctica con la Didáctica Freiriana y quiere ser un avance en la reflexión sobre el proceso de la reinvención del Método Paulo Freire. Para eso, tenemos como base teórica y práctica tres matices: Teología de la Liberación, Educación Liberadora y Filosofía de la Liberación, considerando estas tres fuentes como referencia para la producción de una epistemología latinoamericana que es la base de la praxis de Paulo Freire en la producción de Pedagogía de los Oprimidos. Desde un punto de vista metodológico, describiremos tres formas de usar la didáctica freiriana en diferentes espacios y momentos pedagógicos, sea en la escuela, la universidad o en espacios no formales e informales, son: estrategia pedagógica, trayectoria educativa y caja de herramientas. Aunque se creó recientemente, la didáctica freiriana ha demostrado tener el potencial de reinventar el Método Paulo Freire, basado en las contribuciones teóricas de la Pedagogía de los Oprimidos.

Palabras clave: Didáctica freiriana. Método Paulo Freire. Pedagogía de los oprimidos. Reinvención.

\section{Pedagogia das primeiras palavras}

Este texto trata da Didática Freiriana como uma reinvenção do Método Paulo Freire, que dialoga com as bases teórico-práticas da Pedagogia do Oprimido, servindo de reflexão e orientação para educadores e educadoras, seja na escola ou na universidade ou em espaços não formais e informais, para se servirem do legado de Paulo Freire para redimensionar sua práxis pedagógica.

Nesse sentido, busca-se apresentar, ao longo do artigo, a Didática Freiriana como um potencial pedagógico para educadores e educadoras, que a utilizarão de forma instrumental, embora inacabada, em construção na prática, como uma forma de aproximar a sua ação educativa com a perspectiva crítica de Freire.

Este texto está embasado teoricamente nas obras de Paulo Freire, essencialmente na Pedagogia do Oprimido, em seu terceiro capítulo, no qual o autor apresenta o seu método (que já está muito mais ligado a uma epistemologia da educação), de que resultou a produção de uma Didática própria, embasada no nosso autor de referência. Depois de produzida uma primeira versão da Didática Freiriana (DICKMANN; DICKMANN, 2018), executaram-se diversas oficinas presenciais e on-line, e, a partir daí, redimensionamos e localizamos limites e potencialidades que se apresentarão ao longo deste texto, num processo de releitura e de construção contínua dessa prática freiriana.

Daí surge uma pergunta fundamental: como utilizar a Didática Freiriana para redimensionar a práxis de educadores/as que se dizem freirianos/as? Como fazer isso? Este é o objetivo que este texto vai tentar responder ao longo dos tópicos a seguir, apresentando três possibilidades de uso da didática freiriana, a saber, como estratégia pedagógica, como percurso educativo e como uma "caixa de ferramentas". 
Tendo isso como base, a seguir, apresenta-se um referencial teórico consistente que dará fundamentação para essa prática de forma congruente com o legado freiriano, além de mostrar as três formas de uso prático da Didática Freiriana.

\section{Pedagogia da reflexão}

Nossa reflexão surge da nossa prática e da nossa capacidade de reflexão daquilo que fizemos, nossa práxis, quer dizer, da nossa experiência de vida, que é marcada pela participação em diversos espaços pedagógicos, que vão desde a escola formal até a Educação Popular, como mostraremos em seguida. Ela é fruto da nossa vivência e de como fomos aprendendo e ensinando e, ao mesmo tempo, fomos sistematizando essas experiências, e elas foram se tornando nosso modo de ensinar e aprender, ou seja, nosso jeito de educar.

Nessa direção, temos três matrizes teóricas que permeiam nossa práxis de educadores, a saber: a) Teologia da Libertação; b) Filosofia da Libertação; e c) Educação Libertadora. É a partir do estudo, da reflexão e da produção, tendo como base a amálgama dessas teorias, que construímos uma reinvenção do Método Paulo Freire, que chamamos de Didática Freiriana.

Para ilustrar melhor como essas três teorias contribuíram para a formulação da Didática Freiriana, a seguir, faremos uma breve reflexão sobre como cada uma delas chegou até nós e como nos impactou, de tal modo que nos condicionam a agir tendo-as como referências.

\section{Teologia da Libertação}

A Teologia da Libertação nos foi apresentada na juventude, na experiência junto à Congregação dos Oblatos de São Francisco de Sales. Era meados da década de 1990, e a leitura dos textos de Leonardo Boff $(1980,1994)$, Leonardo Boff e Clodovis Boff (1986), Francisco Catão (1989) e Gustavo Gutiérrez (1985) foi mostrando para nós que haviam opressores e oprimidos, e que essa divisão de classe social não era desejo divino e, de várias maneiras, estávamos envolvidos nesse contexto.

Ao mesmo tempo, íamos aprendendo a teoria e conhecendo os práticos: Dom Helder Câmara (CONDINI, 2014), Dom Pedro Casaldáliga (TAVARES, 2019), Dom Oscar Romero (BINGEMER, 2012), Dom José Gomes (LOVERA et al., 2013), Irmão Antônio Cechin (2010), só para citar alguns do Brasil e de outros países da América Latina. As leituras orientadas pelos padres formadores no seminário eram acom- 
panhadas de pastoral nos finais de semana. Teoria e prática se dialetizavam, ao mesmo tempo em que éramos introduzidos à leitura orante da Palavra de Deus, éramos enviados para as comunidades do interior de Jaboticaba, no Rio Grande do Sul, para viver a missão do Evangelho Vivo: estar entre os oprimidos, ficar no meio do povo, vivenciar as Comunidades Eclesiais de Base (CEBs).

Outra prática comum nesse tempo, tão marcante quanto a pastoral (seja da liturgia como da juventude), era a participação em Romarias da Terra, mobilizações dos movimentos sociais e populares, encontros diocesanos da Pastoral da Juventude, celebração da vida e da luta. Tudo fruto de um planejamento no início do ano e um retiro de revisão de vida ao final do ano. Essa estrutura foi propícia para desenvolvermos uma profunda consciência de classe, aprofundando nossa leitura de mundo, permitindo contribuir na tessitura de outras formas de vida e de relações mais humanas - numa profunda opção preferencial pelos pobres.

Dessa matriz teórica, emerge o método Ver - Julgar - Agir, que orienta uma prática pedagógico-pastoral, permitindo enxergar aspectos educativos nas práticas religiosas, especialmente dentro dessa concepção crítica de Teologia. Havia já uma aproximação dessas teorias e práticas com o que vinha acontecendo em toda a América Latina, que reverberava permanentemente em outras dimensões da vida, como na pedagogia, na filosofia, na sociologia e nas teorias da dependência.

Do ponto de vista prático, vê-se uma unidade crítica - de práticas e teorias - que emergiu nos anos 1960-1970 e que tem como uma das múltiplas facetas a Teologia da Libertação, não como uma construção isolada, mas como parte desse movimento latino-americano. Paulo Freire influenciou e foi influenciado por essas práticas, leu as obras de seus criadores, contribuiu com as reflexões nas CEBs, no exílio e no seu retorno ao Brasil nos anos de 1980, inclusive muitas obras demonstram essa aproximação teológica (CORDAZZO; DICKMANN, 2019; LEOPANDO, 2017; MARTINS, 2011; STRECK, 1991; CAVALCANTI, 1975). Pode-se afirmar, sem sombras de dúvidas, que a produção freiriana dessa época é parte desse arcabouço teórico-crítico e tem no livro Pedagogia do Oprimido a síntese pedagógica mais importante, figurando juntamente com as obras de Gustavo Gutiérrez na Teologia e Enrique Dussel na Filosofia, como os três grandes pilares teóricos desse tempo.

Dessa matriz teológica, fica marcada na Didática Freiriana a fé nas pessoas, na acolhida do ser do outro como ação pastoral e na possibilidade da libertação em comunhão como meta pedagógica. Acolhida é a alteridade colocada em prática, é a efetivação da opção preferencial pelos pobres, é a aceitação da fraqueza e da angústia do outro como sua própria, é a incorporação da diferença como abertura 
ao outro, seu saber e sua ignorância, sua ciência e seu senso comum - superando qualquer forma de discriminação -, é a postura pedagógica da pergunta epistemológica que se abre para a construção do conhecimento contextualizado.

\section{Filosofia da Libertação}

A Filosofia da Libertação, ou Filosofia Latino-americana, nos foi apresentada no Instituto Superior de Filosofia Berthier (Ifibe), em meados dos anos 2000. Ao nos depararmos com as reflexões profundas de Enrique Dussel sobre a realidade latino-americana, imediatamente, percebemos a identidade dela com a perspectiva teológica que nos dava suporte para a ação pastoral. Iniciamos uma leitura desse pensador e de outros que, como ele, iam desenhando a possibilidade de se produzir Filosofia desde o "sul do mundo", libertando-se das produções preconceituosas da filosofia idealista europeia.

Dussel (1980), com sua ampla produção filosófica, construiu um arcabouço filosófico consistente, desde um método para a Filosofia da Libertação (DUSSEL, 1986), até as bases epistemológicas que vão demonstrar a ideologia da exclusão sustentada pelas teorias clássicas com acento numa razão universal e universalizante (DUSSEL, 1995). Nesse processo, mostrou ser possível produzir conhecimento filosófico a partir da América Latina, diferente do que se pensava antes, que só a Europa e a América do Norte filosofavam - o que de imediato já é uma irracionalidade.

Uma das centralidades do pensamento de Dussel, pode-se afirmar entre muitas elaborações, é o sentido de um filosofar autêntico, tomando por base a realidade latino-americana, pensar a partir do contexto oprimido, a necessidade da superação da alienação e a construção da libertação (BOUFLEUER, 1991). Essa possibilidade tem muita identidade com a pedagogia freiriana, que parte do oprimido, seu contexto, sua situação-limite, em vista de construir um inédito viável (FREIRE, 2011).

A Filosofia da Libertação e a ética construída por Dussel (2000) se aproximam da Pedagogia Libertadora de Freire (2011), ao serem produzidas de forma intersubjetiva e pensadas como um processo coletivo dos sujeitos históricos, em vista da conscientização de todos, tendo o diálogo como método e ferramenta para a construção de relações humanas e pedagógicas profundamente éticas. Provavelmente, a descoberta filosófico-pedagógica em comum de Dussel e Freire é que o ser humano oprimido não consegue pensar e aprender, sem que se eduquem a si mesmo e aos 
outros em comunhão em vista da sua libertação - sendo que isso se constitui como um objetivo universal da razão.

Essa matriz filosófica contribui para uma Didática Freiriana reflexiva, que parte da pergunta sobre o contexto concreto dos oprimidos latino-americanos, aceitando-os como sujeitos protagonistas da sua libertação. Aceita a realidade como processo que se faz na disputa política, histórica, pedagógica, econômica, ambiental, cultural e de classe, entre tantas outras dimensões que compõem a totalidade do real. A Filosofia da Libertação de Dussel nos mostra a importância da sistematização da experiência, da práxis, em que os temas geradores emergem da realidade oprimida para serem problematizados e superados. A filosofia é essencial à pedagogia, contribuindo para uma prática reflexiva crítica, em que Freire e Dussel convergem para a criação de uma nova forma de pensar e fazer a pedagogia - Educação Popular - na América Latina com potencial universal.

\section{Educação Libertadora}

A educação freiriana, ou Educação Libertadora, está sustentada em alguns pilares ou princípios. Alguns autores já elaboraram essa síntese, mas vamos retomá-la para demonstrar como está construída a possibilidade de uma educação que tem como foco a libertação dos oprimidos na construção do conhecimento inter-relacional entre educador e educandos.

Embora não seja fácil definir um padrão na produção de Paulo Freire, haja vista a sua matriz ampliada de pensadores e teorias, é possível localizá-lo dentro das perspectivas críticas de educação, estando entre as bases mais profundas que fundamentam as visões pedagógicas emancipatórias e, ainda, é importante ressaltar a relação permanente entre teoria e prática de Freire, como intelectual comprometido e profundamente vinculado à ação transformadora, em vista da mudança dos lugares de vivência (SANTOS, 2017; DICKMANN; DICKMANN, 2020).

Na prática, três pontos são centrais nesse panorama da pedagogia da libertação, centralmente presentes na Pedagogia do Oprimido: a) o diálogo como método; b) a educação como ato político; c) o contexto como ponto de partida gnosiológico. É útil à nossa reflexão ver cada um deles, sabendo que estes se articulam com outros que aparecerão ao longo deste ensaio.

O diálogo é o ponto de partida da relação entre educadores e educandos, tornando-se o modo como o educador constrói conhecimento com os seus educandos, por isso, afirmamos o diálogo como método. Além disso, o diálogo foca na pergunta, 
sem iniciar um trabalho educativo já com as respostas prontas sobre um tema ou conceito. O diálogo implica na não violência, na postura amorosa entre os sujeitos, no respeito mútuo, na diversidade e na diferença, na tolerância, enfim, o diálogo é abertura ao outro, e a educação torna-se diálogo de saberes. Nesse sentido, o diálogo muda as relações de poder no processo pedagógico, sendo agora construído na horizontalidade, na confiança no outro e na intercomunicação, partindo do princípio que todos sabem algo, não há saber mais ou saber menos, mas saberes diferentes, como uma exigência existencial dos seres humanos (FREIRE, 2011; SANTOS, 2017).

Um segundo princípio é a politicidade do ato educativo, afirmando que não há neutralidade nas práticas pedagógicas. Se educar é um ato de mudança - das pessoas e dos contextos nos quais elas estão inseridas -, então, a educação é política, não porque queria Freire, mas porque ela implica numa rede de relações sociais e, portanto, interligadas ao todo da realidade. Há uma ligação política na relação entre quem ensina e quem aprende, assim como há relação política entre as pessoas nas demais esferas da vida pública. A negação da politicidade da educação já é um ato político-ideológico, em torno de uma visão de mundo - distinta desta, obviamente. Por isso, afirma-se a educação como fator de transformação da sociedade, como ato de mudar as pessoas e o mundo. Por ser política, a Educação Libertadora gera participação, é democrática, ao contrário da educação bancária, que é autoritária e gera apatia e silêncio submisso.

Por último, é preciso falar da educação a partir do contexto, ou de como construir conhecimento a partir da realidade dos educadores e educandos. O lugar dos sujeitos como ponto de partida gnosiológico permite encharcar de sentido o processo de produção do conhecimento, visto que uma das descobertas freirianas é que quanto mais próximo do contexto estiver o conteúdo, melhor o educando aprende (GADOTTI, 2001; FREIRE, 2011). O que importa neste princípio, em específico, é que, ao conhecer a realidade do seu entorno de vida, os educandos podem projetar ações transformadoras, já que a produção do conhecimento é uma ação em vista da práxis e da mudança, não simplesmente para acumular saberes, mas para aprofundar a leitura do mundo (que precede a leitura da palavra) na perspectiva do engajamento desses sujeitos no seu mundo mais imediato.

Esses princípios contribuem para a construção de uma Didática Freiriana, que crê no ser humano, no diálogo rigorosamente amoroso, com foco nas perguntas problematizadoras, em que educadores e educandos assumem papel de respeito mútuo, mas também de agentes políticos nas relações e nos processos. As contribui- 
ções da Educação Libertadora latino-americana convergem para uma pedagogia da investigação do contexto concreto e imediato dos sujeitos, pensando e construindo a mudanças das realidades opressoras e desumanizantes, tomando o contexto e as falas dos sujeitos como palavras e temas geradores, em vista de uma práxis transformadora, que posteriormente será sistematizada e publicizada, para ser avaliada pelos protagonistas do processo.

Diante dessa construção teórica, podemos avançar para apresentar as bases práticas da Didática Freiriana como reinvenção do Método Paulo Freire e suas partes intrínsecas, como ela está articulada internamente e o que julgamos mais inovador nesse ensaio é como os educadores - na escola, na universidade, na Educação Popular - podem usar a Didática Freiriana em seus trabalhos pedagógicos.

\section{Pedagogia da reinvenção}

A Didática Freiriana como a pensamos está organizada em dez pedagogias e também em quatro momentos, que vamos apresentar a seguir. Esta organização é analítica, ou seja, serve para estudarmos a didática freiriana e compreendê-la. No cotidiano dos espaços pedagógicos pode sofrer, e normalmente sofre, mudanças de percurso, de execução e até pode ser afetada, recriada pela criatividade do educador ou educadora que ajustará a didática freiriana a sua especificidade. Tudo isso sem perder a essência que compartilhamos.

O primeiro momento chamamos de Momento Propedêutico e é composto pelas pedagogias da acolhida e pela pedagogia da pergunta. Neste momento, o/a educador/a faz sua aproximação com a sua turma e a acolhe com alguma dinâmica de grupo, um jogo coletivo para descontrair e "quebrar o gelo". Mas também recebe seus educandos e educandas por inteiro, demonstra que está de braços abertos para construir um espaço pedagógico plural, múltiplo. Consolida a ideia de que diversidade cabe e é bem-vinda neste ambiente unificador.

Como dissemos, duas pedagogias compõem este momento. A primeira é a pedagogia da acolhida, entendida aqui como momento da humanização. A acolhida é a dialetização das duas grandes dimensões humanas: a afetividade e a racionalidade. Acolher é respeitar o conhecimento dos outros - popular, acadêmico-científico, místico-religioso -, é proporcionar o diálogo de saberes. Se recepciona a pessoa, também as suas ideias. A segunda pedagogia que compõem o momento introdutório é a pedagogia da pergunta, que é o diálogo feito práxis, é curiosidade que se externaliza na palavra, como assinala Guerrero (2010, p. 53): "Todo conhecimen- 
to começa pela pergunta”. A pergunta desperta a curiosidade e a criatividade do educando. A pedagogia da pergunta é a antítese da pedagogia tradicional que se sustenta na estratégia da resposta pronta, antidialógica e opressora.

O segundo momento da didática freiriana é o Momento Investigativo. Ele é composto pela pedagogia do tema gerador, pedagogia da contextualização e pedagogia da reflexão. É hora de começar a identificar e analisar o mundo dos educandos e educandas (que é o mundo do educador/a também), para iniciar o desenho do conteúdo programático. Este deve emergir e estar conectado com a realidade da turma. Esse contexto concreto é a base sobre a qual se construirão os próximos passos do processo pedagógico. Só faz sentido refletir, se refletirmos sobre o mundo no qual estamos inseridos, e não simplesmente elucubrar sobre abstrações que não poderemos intervir e transformar.

Vamos ver as pedagogias que conformam este momento pedagógico. Começamos pela pedagogia do tema gerador, que é uma das originalidades da pedagogia freiriana, ele é resultado da reflexão crítica em torno das situações-limites, da codificação do universo vocabular e das temáticas significativas dos grupos que vamos trabalhar. A pedagogia do tema gerador é o momento da continuidade da reflexão do que emerge da pedagogia da pergunta. Na pedagogia da contextualização, entendemos que o conhecimento se constrói a partir do contexto concreto. Esse momento de contextualização é preparatório para pensar as ações de mudança, é o tempo de aprofundar a leitura de mundo, contextualizando o saber que é produzido no diálogo libertador. Adiante, encontramos a pedagogia da reflexão. Refletir é pensar de forma crítica sobre alguma realidade ou algum objeto, é um ato de autonomia intelectual, exige do sujeito a responsabilidade epistemológica para captar da melhor forma possível a totalidade de aspectos que se manifestam no real. A reflexão é a antecipação da ação transformadora, ato coletivo e emancipador, que projeta a possibilidade da concretude da mudança das pessoas e do mundo.

Chegamos ao terceiro momento da didática freiriana, o Momento Propositivo. Ele é composto por mais três pedagogias, a pedagogia da investigação temática, pedagogia da práxis e a pedagogia da sistematização. É chegada a hora de modelar a operatividade de nossa intervenção pedagógica. Temos já os elementos necessários para a práxis educativa, construídos nos momentos anteriores. Esta práxis deve se dedicar aos problemas encontrados no diálogo entre educador/a e educandos/as, em vista de soluções que sustentem uma transformação estrutural. Agir e refletir, refletir o agir. Sistematizar a prática para poder fazer ainda melhor, este é o momento. 
A pedagogia da investigação temática, que é uma das que compõem este momento pedagógico, dedica-se a nos levar à ação transformadora sobre a realidade refletida. É aqui que há um aprofundamento da leitura de mundo para compreender melhor o mundo para agir e mudar. Precisamos avançar depois do diálogo e da construção do conhecimento enquanto ato pedagógico libertador, para a organização da práxis coletiva. A pedagogia da práxis implica na ação-reflexão-ação como processo de descoberta coletiva do mundo, do pronunciamento do mundo que queremos, da concretização dos atos-limites transformadores, da superação das situações-limites e da projeção dos inéditos viáveis. A pedagogia da sistematização exige que o processo seja sistematizado, que o diálogo em torno do objeto do conhecimento possa ser acessado por todos e todas, precisa ser publicizado, publicado, escrito. Precisa retomar o pretexto de origem da discussão em proximidade com o debate do contexto concreto que se faz texto através do diálogo intersubjetivo, numa "reconstrução ordenada da experiência" (JARA, 2006, p. 22).

Finalmente, no quarto momento da didática freiriana, temos o Momento de Fechamento. Composto pelas pedagogias do diálogo e da gratidão, é o momento que encaminha o encerramento do ciclo pedagógico. Fechar um ciclo é sinal de que seus objetivos foram concluídos, conquistados e que podemos nos despedir, mais completos, mais plenos, renovados e animados em nossa mística coletiva. Neste momento da didática freiriana, temos a presença de pessoas mais maduras, que se dispuseram a um percurso formativo comum desafiador. Por isso, é um tempo de abertura a novas possibilidades diante de aprendizagens construídas no coletivo.

Duas pedagogias se apresentam aos envolvidos neste momento. Primeiro, a pedagogia do diálogo. Nota-se que o conhecimento acontece na interação comunicativa entre os sujeitos, mediatizados no mundo e com o mundo, e possui uma condição dupla para se efetivar: "[...] uma, cognoscitiva, a apreensão da realidade; outra, comunicativa, o diálogo em torno do significado e sentido da realidade apreendida e ressignificada [...]" (BRUTSCHER, 2005, p. 88). Precisamos dialogar com os outros sobre os nossos saberes para legitimar e aprofundar nossa compreensão da realidade. Depois, temos a pedagogia da gratidão. Ela nos recorda que não produzimos nada sozinhos, que somos seres de relação, intersubjetivos, interdependentes. Nesse sentido, precisamos ser gratos, dizer obrigado a quem caminha junto, lado a lado, mão na mão. Isso atrai mais gente, é parte da pedagogia do encantamento e da alteridade, torna-se pedagogia da gratidão.

No Quadro 1, temos uma síntese dos quatro momentos que acabamos de ver. 
Quadro 1 - Quatro momentos da didática freiriana

\begin{tabular}{|l|l|l|l|}
\hline Momento Propedêutico & Momento Investigativo & Momento Propositivo & \multicolumn{1}{|c|}{$\begin{array}{l}\text { Momento de } \\
\text { Fechamento }\end{array}$} \\
\hline Pedagogia da Acolhida & $\begin{array}{l}\text { Pedagogia do Tema } \\
\text { Gerador }\end{array}$ & $\begin{array}{l}\text { Pedagogia da Investigação } \\
\text { Temática }\end{array}$ & Pedagogia do Diálogo \\
\hline Pedagogia da Pergunta & $\begin{array}{l}\text { Pedagogia da } \\
\text { Contextualização }\end{array}$ & Pedagogia da Práxis & $\begin{array}{l}\text { Pedagogia da } \\
\text { Gratidão }\end{array}$ \\
\hline & Pedagogia da Reflexão & Pedagogia da Sistematização & \\
\hline
\end{tabular}

Fonte: elaboração dos autores.

Entre cada um desses momentos da didática freiriana, propomos aos educadores e educadoras uma Pausa Pedagógica, que é um breve momento no qual você deve parar, pensar e anotar as aprendizagens que o momento proporcionou. Assim, não se perde as primeiras impressões ao longo do processo. Ela está encaixada sempre entre os momentos. No meio do processo é um bom momento para se fazer esses registros e não perder o "fio da meada". Pensamos que, dessa forma, o processo se mantém mais presente e não se dilui na caminhada. Essa pausa é especialmente útil em processos mais longos, pois é natural que não decoremos tudo na nossa cabeça, como se fôssemos gravadores. Como já afirmado por Dickmann (2019, p. 76):

O resgate do passo a passo, do conteúdo, das dinâmicas de grupo, dos diálogos, do método usado é útil para não perdermos o acúmulo da caminhada. Uma pausa pedagógica potencializa o que vai ser ensinado a seguir, pois os educandos e o educador refrescam as suas memórias e prosseguem com a compreensão dos temas mais nítidos.

Não se avança sem ter a certeza de que todos estamos aprendendo ao avançar. Nesse sentido, a pausa pedagógica ajuda a rememorar o passo a passo realizado até cada parada e reforça o que será ensinado na sequência do processo. Desde que acrescentamos a pausa pedagógica em nossos processos, notamos uma força maior nos encontros. Nossos novos saberes vão se ajustando na prática e na reflexão, no uso desses conhecimentos. A pausa pedagógica garante que consigamos acumular mais saberes. Experimente!

Como processo em construção, vislumbramos o uso da didática freiriana em, pelo menos, três formas em nosso quefazer pedagógico. Não determinamos qual é a melhor maneira de usá-la, pois nós não conhecemos tão profundamente sua rea- 
lidade a ponto de dar esta orientação. Contudo, acreditamos que os três caminhos poderão nos levar ao mesmo ponto com o passar do tempo.

As três formas são: 1) como uma estratégia pedagógica, iluminando todas as suas ações e intervenções pedagógicas; 2) como um percurso educativo, a ser utilizado de forma sequenciada, da primeira pedagogia até a última; 3) como uma caixa de ferramentas, numa visão mais livre, podendo utilizar as pedagogias conforme a necessidade pedagógica assinalar. Veja qual pode ser a sua postura pedagógica perante a didática freiriana.

Estratégia Pedagógica: quando nos referimos à estratégia, queremos dizer que você recorrerá à didática freiriana como uma diretriz para suas atividades pedagógicas. Sempre que você estiver em dúvida do que fazer, sempre que tiver que modelar alguma intervenção, você lembrará dos princípios presentes nas dez pedagogias que compõem a didática freiriana.

Esta perspectiva coloca a didática freiriana no campo estratégico, como seu próprio nome diz, ou seja, ela iluminará sua ação como uma diretriz centralizadora, não deixando você se perder. Será seu farol, conduzindo você de forma segura no seu quefazer educativo. Dessa forma, você não desliza de uma intervenção crítica e criticizante e terá a seu favor a pedagogia freiriana como suporte.

Fazer da didática freiriana nossa estratégia pedagógica é ter clareza de que tipo de intervenção educativa estamos dispostos a concretizar. Um modo de educar transformador, em que a realidade se impõe ao espaço educativo como ponto de partida e de chegada numa visão dialética do mundo, em que tensionamos para transformar e somos tensionados por esta realidade com vistas a sua manutenção.

Percurso Educativo: pode-se, também, usar os quatro momentos e as dez pedagogias como um caminho gradual para preparar as ações educativas. Iniciar a jornada com a pedagogia da acolhida e finalizar com a pedagogia da gratidão. Esta visão de percurso é muito útil enquanto estamos aprendendo e dominando as dez pedagogias, num processo de aproximação da didática freiriana.

Imagine-se preparando uma intervenção pedagógica. Planeje-a em seus quatro momentos, passo a passo. Como podemos introduzir para acolher a turma e estimular os primeiros diálogos? Como vamos iniciar a fase investigativa e extrair as informações que precisamos? Como podemos modelar, com a participação dos educandos/as, as ações concretas? E, por fim, como dialogar e agradecer no fechamento de sua jornada.

Repare que, desta maneira, vamos passando cada uma das pedagogias constituintes da didática freiriana. Ao vivenciá-las, aprendemos a dominar seu sentido 
e sua função no percurso formativo. Depois de algumas execuções, podemos nos sentir mais seguros para usar a imaginação e a criatividade para ousar e construir nosso próprio percurso. Somente devemos tomar cuidado para não deixar faltar algum elemento que a turma precise para compreender o tema estudado. A criatividade deve ser usada com responsabilidade, mas, por certo, que deve ser usada.

Caixa de Ferramentas: neste cenário, podemos ter duas dinâmicas. Na primeira, podemos já estar utilizando algumas das dez pedagogias no nosso quefazer pedagógico de forma intuitiva, e, então, vamos acrescentando as demais com o decorrer do tempo até acumular todas e ter certeza de que cada uma delas se fez presente no processo educativo; na segunda, podemos ver as dez pedagogias de forma - mais ou menos - isolada e utilizar aquela que for mais útil em determinada ocasião. Numa abertura de turma nova, por exemplo, pode intensificar a pedagogia da acolhida, enquanto que numa turma que já está mais tempo junto pode aprofundar os diálogos com a pedagogia da reflexão e da investigação temática.

Temos presente que educadores/as, ao tomarem contato com a proposta da didática freiriana, poderão estar no meio de um processo com alguma turma, e, para nós, não faz sentido parar tudo e recomeçar do zero com a didática freiriana. Portanto, a visão de uma "caixa de ferramentas" pode ser útil no sentido de enriquecer a intervenção pedagógica a partir de onde já nos encontramos.

Cabe também trazer uma característica da caixa de ferramentas. Ela depende da ação humana para realizar seu potencial. Vejamos, podemos ter a nossa disposição a didática freiriana com suas dez pedagogias, seus quatro momentos pedagógicos, mas, se não agirmos de forma a dar concretude a essas possibilidades, nada acontecerá. Tenhamos isso sempre no nosso horizonte, a didática freiriana prescinde do nosso compromisso de fazer, de nossa tarefa educativa consciente.

\section{Pedagogia da (in)conclusão...}

O objetivo principal deste texto era fazer uma retomada da nossa práxis histórico-pedagógica e, com isso, elucidar as bases teórico-práticas da Didática Freiriana, tendo em vista que ainda é um processo em construção, estando aberto à contribuição de outros educadores para dar a ela mais consistência. Como demonstramos, ela está embasada em três matrizes teóricas muito claras: a Teologia da Libertação, a Filosofia da Libertação e a Educação Libertadora. Todas com raízes nos movimentos críticos da América Latina, com início nos anos 1960-1970, dos quais nós construímos uma amálgama densa para a reinvenção da práxis freiriana. 
Nesse caminho, é pertinente ao final do trabalho apresentarmos algumas considerações indicativas de como utilizar a Didática Freiriana na prática cotidiana, como forma propositiva de ilustrar aos/às educadores/as - lembrando sempre que essa prática não pode estar descolada da teoria crítica apresentada no referencial que a embasa:

a) fazer oficinas pedagógicas utilizando a Didática Freiriana como um percurso metodológico - uma espécie de começo, meio e fim - do encontro, permitindo saber exatamente o que fazer em cada momento;

b) realizar cursos on-line sobre Paulo Freire e seu Método, tendo a Didática Freiriana como pano de fundo dos encontros, podendo constituir-se como uma série de eventos ao vivo, transmitidos pelas plataformas digitais;

c) promover sistematizações de experiências pedagógicas por meio de artigos científicos, trabalhos de conclusão de curso, dissertações e teses, tendo a metodologia de Freire e a Didática Freiriana como aporte epistêmico-metodológico;

d) motivar os educadores populares a resgatar seu papel de protagonistas e lideranças revolucionárias, reanimando sua práxis e reencantando sua ação educativa a partir da Didática Freiriana.

Independentemente das diversidades de formas de fazer ou dos usos que se darão para a Didática Freiriana, o presente texto tem a intenção de dar fundamentos a uma prática baseada na Pedagogia do Oprimido de Freire e que se amplia nos aspectos filosóficos e teológicos dos criadores dessa didática em específico.

Espera-se que os leitores venham a aderir à Didática Freiriana, ampliando as experiências com ela, diversificando seus usos, possibilitando novas reflexões, inserindo e extraindo "pedagogias", a fim de aprimorá-la, contribuindo para a reinvenção do Método de Paulo Freire e a disseminação de seu legado, mais de 20 anos depois de sua morte e 50 anos depois da Pedagogia do Oprimido.

\section{Referências}

BINGEMER, M. C. (org.). Dom Oscar Romero: Mártir da Libertação. Aparecida: Santuário, 2012.

BOFF, L. Igreja: carisma e poder. São Paulo: Ática, 1994.

BOFF, L. Teologia do cativeiro e da libertação. São Paulo: Círculo do Livro, 1980.

BOFF, L.; BOFF, C. Como fazer teologia da libertação. Petrópolis: Vozes, 1986. 
BOUFLEUER, J. P. Pedagogia Latino-americana: Freire e Dussel. Ijuí: Editora da Unijuí, 1991. (Coleção Educação; 12).

BRUTSCHER, V. J. Educação e conhecimento em Paulo Freire. Passo Fundo: IFIBE; IPF, 2005. (Coleção Diá-Lógos; 07).

CATÃO, Francisco. O que é Teologia da Libertação. São Paulo: Brasiliense, 1989.

CAVALCANTI, T. M. P. Tentativa de uma leitura teológica do pensamento de Paulo Freire. Revista Síntese, Rio de Janeiro, n. 5, v. 2, p. 87-99, out./dez. 1975.

CECHIN, A. Empoderamento popular: uma pedagogia da libertação. Porto Alegre: ESTEF, 2010.

CONDINI, M. Fundamentos para uma Educação Libertadora: Dom Helder Câmara e Paulo Freire. São Paulo: Paulus, 2014. (Coleção Educação Superior).

CORDAZZO, D. P.; DICKMANN, I. Contribuições de Paulo Freire para o Ensino Religioso não confessional. In: SIMONI, J. C.; CECCHETTI, E. (org.). Ensino Religioso não confessional: múltiplos olhares. São Leopoldo: Oikos, 2019. p. 52-63.

DICKMANN, I. (org.). Pedagogia da gratidão. São Paulo: Dialogar, 2017.

DICKMANN, I. Oficinas pedagógicas de Didática Freiriana. In: DICKMANN, I. (org.). Diálogo freiriano: cartas, relatos e artigos. Veranópolis: Diálogo Freiriano, 2019. p. 73-78.

DICKMANN, I.; DICKMANN, I. Didática Freiriana: reinventando Paulo Freire. Educere et Educere, Cascavel, v. 13, n. 28, maio/ago. 2018. DOI: http://dx.doi.org/10.17648/educare. v13i28.18076.

DICKMANN, I.; DICKMANN, I. Primeiras palavras em Paulo Freire. 3. ed. Chapecó: Livrologia, 2019.

DICKMANN, I.; DICKMANN, I. Paulo Freire: método e didática. Chapecó: Livrologia, 2020. (Coleção Paulo Freire; 03).

DUSSEL, E. Filosofia da Libertação na América Latina. Piracicaba: Unimep; São Paulo: Loyola, 1980 .

DUSSEL, E. Método para uma Filosofia da Libertação. São Paulo: Loyola, 1986.

DUSSEL, E. Filosofia da Libertação: crítica à ideologia da exclusão. São Paulo: Paulus, 1995. (Coleção Pesquisa e Projeto).

DUSSEL, E. Ética da Libertação na idade da globalização e da exclusão. Petrópolis: Vozes, 2000.

FREIRE, P. Pedagogia do oprimido. Rio de Janeiro: Paz e Terra, 2011.

GADOTTI, M. Um legado de esperança. São Paulo: Cortez, 2001. (Coleção Questões da Nossa Época; 91).

GUERRERO, M. E. Sonhos e utopias: ler Freire a partir da prática. Brasília: Líber Livro, 2010. GUTIÉRREZ, G. Teologia da Libertação: perspectivas. Petrópolis: Vozes, 1985. 
JARA, O. Para sistematizar experiências. 2. ed. Brasília, DF: Ministério do Meio Ambiente, 2006. (Série Monitoramento e Avaliação; 02).

LEOPANDO, I. A pedagogy of faith: the theological vision of Paulo Freire. New York: Bloomsbury, 2017.

LOVERA, C. J. et al. (org.). Sermões do Bispo Dom José Gomes. Florianópolis: Premier, 2013. (Série Documentos; 07).

MARTINS, E. S. Paulo Freire e a Teologia da Liberação: aproximações. São Paulo: Editora Reflexão, 2011.

SANTOS, J. A. Aportes para una pedagogía crítica nuestroamericana: identificando el núcleo conceptual del pensamiento político-pedagógico de Paulo Freire. Revista Pedagógica, Chapecó, v. 19, n. 41, p. 80-95, maio/ago. 2017. DOI: http://dx.doi.org/10.22196/rp.v19i41.3801.

STRECK, D. Paulo Freire: uma leitura a partir da educação cristã. Revista Estudos Teológicos, São Leopoldo, v. 31, n. 3, p. 270-283, 1991.

TAVARES, A. H. Um bispo contra todas as cercas: a vida e as causas de Pedro Casaldáliga. Rio de Janeiro: Gramma, 2019. 